\title{
A rare case of acute angle closure due to spontaneous suprachoroidal haemorrhage secondary to loss of anti-coagulation control: a case report
}

\author{
Ibrahim Masri, Jonathan M. Smith, Nicholas K. Wride and Saurabh Ghosh
}

\begin{abstract}
Background: Suprachoroidal haemorrhage is a rare complication of either medical anticoagulation treatment or intraocular surgical procedures. Suprachoroidal haemorrhages often have devastating visual outcome despite conservative and/or surgical intervention.

Case presentation: A patient with known Open Angle Glaucoma and Atrial Fibrillation on warfarin presents symptoms and signs suggestive acute angle closure. Examination reveals the underlying cause is a large, macula involving, spontaneous suprachoroidal haemorrhage secondary to loss of anti-coagulation control. Following aggressive medical treatment and surgical intervention, including drainage combined cataract extraction with intraocular lens implant, pars-plana vitrectomy, and external drainage of suprachoroidal haematoma, we managed to preserve the patient's eye and some of its function.

Conclusion: Spontaneous suprachoroidal haemorrhages are rare complications of loss of anticoagulation control. Our case shows that aggressive treatment in selected cases can offer a relatively good outcome.
\end{abstract}

Keywords: Suprachoroidal haemorrhage, Acute angle closure, Anticoagulation

\section{Background}

Suprachoroidal haemorrhage is a rare complication of intraocular surgery or trauma. Even more rarely it may be spontaneous. Risk factors include older age, patients on systemic anticoagulation, systemic hypertension, atherosclerosis, age-related macular degeneration and chronic kidney disease. When they occur, Suprachoroidal haemorrhages often have devastating visual outcome despite conservative and/or surgical intervention [1-3].

\section{Case presentation}

We present a case of acute angle closure due to spontaneous suprachoroidal haemorrhage secondary to loss of anti-coagulation control.

A 67-year-old man, who recently returned from a holiday abroad, presented with a one-day history of worsening right visual acuity and 4 day history of increasing

\footnotetext{
* Correspondence: Ibrahim.masri@doctors.net.uk
}

Sunderland Eye Infirmary, Sunderland, UK right retro-bulbar pain not relieved with simple analgesia.

He had a past medical history of essential tremor managed with Propranolol, Atrial Fibrillation on anticoagulation with Warfarin $4 \mathrm{mg}$ daily - target International Normalised Ratio (INR) 2.5. Possible confusion with his tablets in the week leading up to the start of his symptoms.

Our patient was also known to have normal tension glaucoma (NTG) managed with Latanoprost. He had Selective Laser Trabeculoplasty (SLT) to the right eye 12 months before to improve his intraocular pressure control. His last recorded visual acuity (VA) was $6 / 6$ in both eyes.

On examination the patient was found to have reduced $\mathrm{VA}$ in the right eye $6 / 12$ with an injected conjunctiva, cloudy cornea and a mid-dilated pupil with a very shallow anterior chamber (AC) and closed irido-corneal angle on gonioscopy (Figs. 1 and 2). Fundus exam revealed a large

(c) The Author(s). 2018 Open Access This article is distributed under the terms of the Creative Commons Attribution 4.0 International License (http://creativecommons.org/licenses/by/4.0/), which permits unrestricted use, distribution, and 


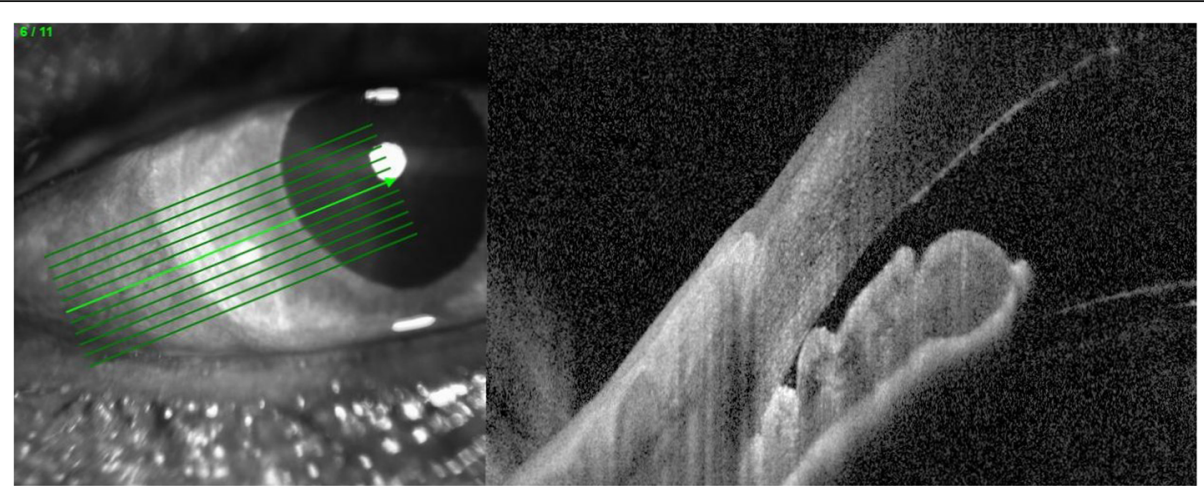

Fig. 1 Right eye anterior segment optical coherence tomography (OCT) showing a closed iridocorneal angle

supero-nasal suprachoroidal haemorrhage not involving the macula. His right intra-ocular pressure (IOP) was $42 \mathrm{mmHg}$. The left eye had a VA of 6/6 with a deep AC and IOP of $12 \mathrm{mmHg}$ (Fig. 3). He was therefore diagnosed with acute angle closure secondary to spontaneous suprachoroidal haemorrhage. His INR measured at $>8$. The patient was given $1 \mathrm{mg}$ of Vitamin $\mathrm{K}$ to reverse his INR, which quickly came down to 5.1. Advice was taken from the general physicians' team and no further Vitamin $\mathrm{K}$ doses were given.

He was started on maximal topical and systemic IOP lowering treatment including G. Apraclonidine 1\% TDS, G. Latanoprost $0.005 \%$ ON, G. Brinzolamide/Timolol (Azarga ${ }^{\circ}$ ) and Oral Acetaolamide $250 \mathrm{mg}$ QDS as well as cycloplegia with G. Atropine 1\% OD.

After $12 \mathrm{~h}$ the IOP was $27 \mathrm{mmHg}$ and INR 3.1. But unfortunately, in the following $12 \mathrm{~h}$, the patient had a second bleed, and his IOP went up to $42 \mathrm{mmHg}$ and VA was down to finger counting. There was no view of the fundus due to corneal edema. B-Scan Ultrasound showed an extension of the suprachoroidal haemorrhage, covering 360 degrees and involving the fovea (Fig. 4).

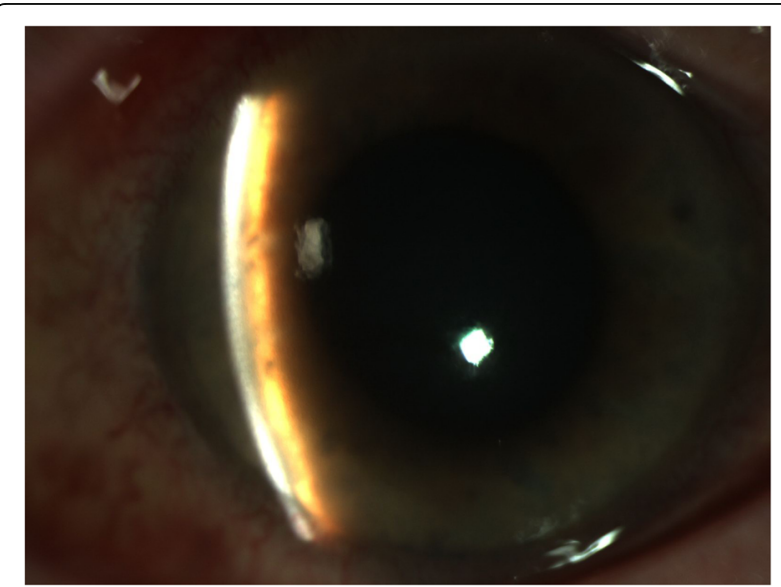

Fig. 2 Slit lamp photo of the right eye
For the next 7 days the patient's remained on the same medical treatment and his IOP was stable in the high 20s. A decision was taken to perform a combined phacoemulsification and lens implant, pars-plana vitrectomy and suprachoroidal haematoma drainage under general anesthesia. (Additional file 1).

Six weeks post operatively the patient had a wide-open angle with a central IOL and a flat retina (Figs. 5 and 6). Intraocular Pressure without IOP lowering treatment was recorded at $20 \mathrm{mmHg}$ with VA 6/24. He was restarted on IOP lowering topical treatment (G Brinzolamide/Timolol BD).

\section{Discussion}

Subconjunctival haemorrhage, and to a lesser extent spontaneous hyphema are the most common ocular complications of loss of anti-coagulation control [4-6]. Spontaneous suprachoroidal haemorrhage causing acute secondary angle-closure glaucoma is a rare ocular disorder [7]. The proposed mechanism for the angle-closure is the abrupt forward displacement of the lens-iris diaphragm, resulting from a massively detached choroid and retina. A similar mechanism also occurs with serous ciliochoroidal detachments in cases of uveal effusion syndrome, nanophthalmos, scleral buckling procedures, panretinal photocoagulation, central retinal vein obstruction, retinopathy of prematurity, scleritis, pars planitis, Harada's disease, acquired immunodeficiency syndrome,

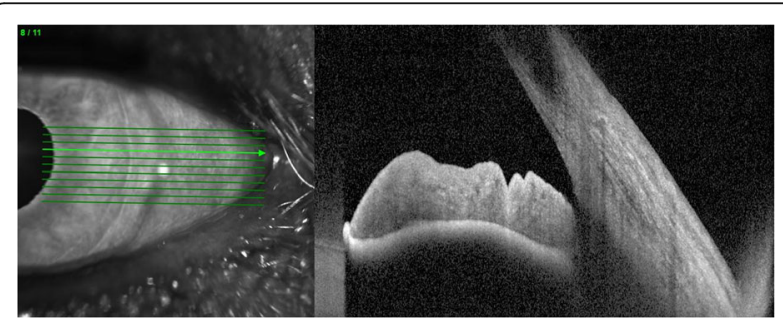

Fig. 3 Left eye Anterior Segment OCT showing an open iridocorneal angle 


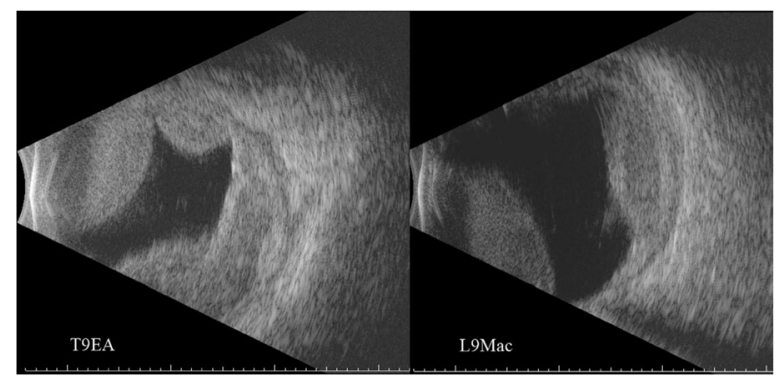

Fig. 4 Ultrasound B-Scan of the right eye showing extensive suprachoroidal haemorrhage involving the center of the macula

and arteriovenous fistulas [8]. Posterior uveal melanoma can present with a spontaneous subretinal or intravitreal haemorrhage which can give rise to an acute or chronic angle closure glaucoma $[9,10]$.

In our patient, loss of coagulation control was due to confusion over two different tablets of the same color. He uses a Monitored Self Dosage (MSD) system, that he organizes himself, when he goes away from home for several days. We postulate that our patient made an error while organizing his MSD system prior to going on holiday. The consequence was inadvertent warfarin overdose, causing loss of anticoagulation control, which led to the spontaneous suprachoroidal haemorrhage in the right eye.

Warfarin belongs to the Coumarin group of Vitamin $\mathrm{K}$ antagonists (VKA). It is the most commonly used VKA anticoagulant. Warfarin is usually reversed using systemic administration of vitamin $\mathrm{K}$ (commonly a single dose of $0.5 \mathrm{mg}-1 \mathrm{mg}$ ). However in cases of life or sight threatening haemorrhages, other agents are available to aided quicker control of coagulation. These are Prothrombin complex concentrate (PCC). Due to the rare nature of such severe bleeds within Ophthalmology practice, the option of PCC use was not considered initially. We can argue that the second haemorrhage could have been avoided if the INR was reversed more aggressively.

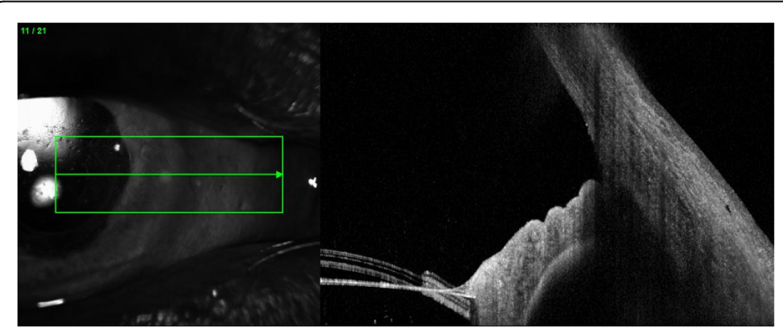

Fig. 5 Right eye post operative anterior segment appearance showing a wide open iridocorneal angle

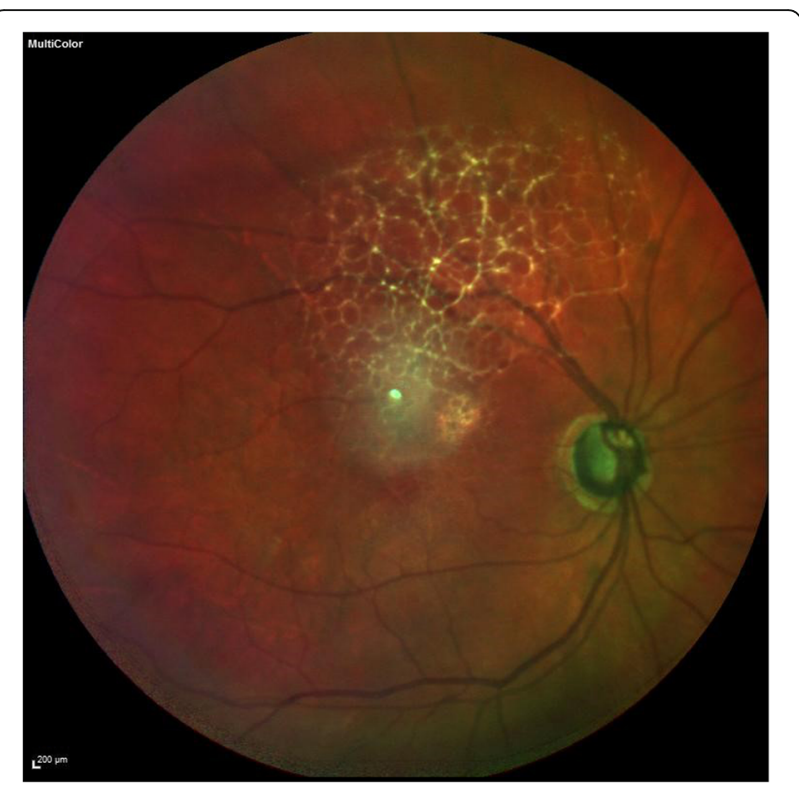

Fig. 6 Multicolor photo of the right eye fundus showing a flat retina post operatively

\section{Conclusion}

The case describes a rare entity of acute angle closure due to spontaneous suprachoroidal haemorrhage secondary to loss of anti-coagulation control. Most of the previously reported cases of angle-closure glaucoma from massive hemorrhagic retinal or choroidal detachments have failed to respond to medical therapy and needed enucleation or retrobulbar injection treatment for pain [11-13]. Early recognition of this rare entity is vital in preserving the function of the eye. Aggressive medical and surgical treatment with suprachoroidal haematoma drainage offers some chance of preserving the eye and some of its function.

\section{Additional file}

Additional file 1: Video of the combined phacoemulsification and lens implant, pars-plana vitrectomy and suprachoroidal haematoma drainage. (AVI $16420 \mathrm{~kb}$ )

\section{Abbreviations}

AC: Anterior chamber; INR: International Normalised Ratio; IOP: Intra-ocular pressure; MSD: Monitored Self Dosage; NTG: Normal tension glaucoma;

OCT: Optical coherence tomography; PCC: Prothrombin complex concentrate; SLT: Selective Laser Trabeculoplasty; VA: Visual acuity; VKA: Vitamin K antagonists

\section{Funding}

This supplement and the meeting on which it was based were sponsored by Novartis (tracking number OPT17-C041). Novartis did not contribute to the content and all authors retained final control of the content and editorial decisions. Novartis have checked that the content was compliant with the Association of the British Pharmaceutical Industry Code of Practice.

Availability of data and materials

All data generated or analysed during this study are included in this published article. 


\section{About this supplement}

This article has been published as part of BMC Ophthalmology Volume 18 Supplement 1, 2018: The Novartis Ophthalmology Case Awards 2017. The full contents of the supplement are available online at https://

bmcophthalmol.biomedcentral.com/articles/supplements/volume-18supplement-1.

\section{Authors' contributions}

IM authored the manuscript. SG, JMS and NKW proofread the manuscript. All authors were directly involved in the care of the patient. All authors read approved the final manuscript.

\section{Ethics approval and consent to participate}

Not applicable.

\section{Consent for publication}

Written consent for publication had been obtained from the patient.

\section{Competing interests}

The authors declare that they have no competing interests.

\section{Publisher's Note}

Springer Nature remains neutral with regard to jurisdictional claims in published maps and institutional affiliations.

Published: 14 September 2018

\section{References}

1. Chu TG, Green RL. Suprachoroidal hemorrhage. Surv Ophthalmol. 43:471-86. http://www.ncbi.nlm.nih.gov/pubmed/10416790. Accessed 28 Nov 2016

2. De Marco R, Aurilia P, Mele A. Massive spontaneous choroidal hemorrhage in a patient with chronic renal failure and coronary artery disease treated with Plavix. Eur J Ophthalmol. 19:883-6. http://www.ncbi.nlm.nih.gov/ pubmed/19787616. Accessed 28 Nov 2016

3. Yang SS, Fu AD, McDonald HR, Johnson RN, Ai E, Jumper JM. Massive spontaneous choroidal hemorrhage. Retina. 2003;23:139-44. http://www. ncbi.nlm.nih.gov/pubmed/12707590. Accessed 28 Nov 2016

4. Holden R. Spontaneous hyphaema as a result of systemic anticoagulation in previously abnormal eyes. Postgrad Med J. 1991;67:1008-10. http://www. ncbi.nlm.nih.gov/pubmed/1775406. Accessed 28 Nov 2016

5. Koehler MP, Sholiton DB. Spontaneous hyphema resulting from warfarin Ann Ophthalmol. 1983;15:858-9. http://www.ncbi.nlm.nih.gov/pubmed/ 6660730. Accessed 28 Nov 2016

6. Kageler W, Moake JL, Garcia CA. Spontaneous hyphema associated with ingestion of aspirin and ethanol. Am J Ophthalmol. 1976;82:631-4. http:// www.ncbi.nlm.nih.gov/pubmed/970426. Accessed 28 Nov 2016

7. Gordon DM, Mead J. Retinal hemorrhage with visual loss during anticoagulant therapy: case report. J Am Geriatr Soc. 1968;16:99-100. http:// www.ncbi.nlm.nih.gov/pubmed/5634475. Accessed 1 Dec 2016

8. Fourman S. Angle-closure glaucoma complicating ciliochoroidal detachment. Ophthalmology. 1989;96:646-53. http://www.ncbi.nlm.nih.gov/ pubmed/2664629. Accessed 1 Dec 2016

9. Fraser DJ, Font RL. Ocular inflammation and hemorrhage as initial manifestations of uveal malignant melanoma. Incidence and prognosis. Arch Ophthalmol (Chicago, III 1960). 1979;97:1311-4. http://www.ncbi.nlm. nih.gov/pubmed/313204. Accessed 1 Dec 2016

10. Yanoff M. Glaucoma mechanisms in ocular malignant melanomas. Am J Ophthalmol. 1970;70:898-904. http://www.ncbi.nlm.nih.gov/pubmed/ 5490617. Accessed 1 Dec 2016

11. Cahn PH, Havener WH. Spontaneous massive choroidal hemorrhage. With preservation of the eye by sclerotomy. Am J Ophthalmol. 1963;56:568-71. http://www.ncbi.nlm.nih.gov/pubmed/14070707. Accessed 1 Dec 2016

12. Wood WJ, Smith TR. Senile disciform macular degeneration complicated by massive hemorrhagic retinal detachment and angle closure glaucoma. Retina. 3:296-303. http://www.ncbi.nlm.nih.gov/pubmed/6201973. Accessed 1 Dec 2016

13. Steinemann T, Goins K, Smith T, Amrien J, Hollins J. Acute closed-angle glaucoma complicating hemorrhagic choroidal detachment associated with parenteral thrombolytic agents. Am J Ophthalmol. 1988;106:752-3. http:// www.ncbi.n/m.nih.gov/pubmed/3195662. Accessed 1 Dec 2016.

Ready to submit your research? Choose BMC and benefit from:

- fast, convenient online submission

- thorough peer review by experienced researchers in your field

- rapid publication on acceptance

- support for research data, including large and complex data types

- gold Open Access which fosters wider collaboration and increased citations

- maximum visibility for your research: over $100 \mathrm{M}$ website views per year

At $\mathrm{BMC}$, research is always in progress.

Learn more biomedcentral.com/submissions 